SŁAWOMIR FuTYMA

Uniwersytet im. Adama Mickiewicza

w Poznaniu

\title{
ZMYSEY I EDUKACJA. \\ O ROLI DOŚWIADCZENIA, WIEDZY ORAZ SELEKCJI (REFLEKSJA FILOZOFICZNA W EDUKACJI)
}

\begin{abstract}
Aвstract. Futyma Sławomir, Zmysty i edukacja. O roli doświadczenia, wiedzy oraz selekcji (refleksja filozoficzna w edukacji) [About the Role of the Senses, Experience and Selection in Education]. Studia Edukacyjne nr 45, 2017, Poznań 2017, pp. 67-75. Adam Mickiewicz University Press. ISSN 1233-6688. DOI: 10.14746/se.2017.45.6
\end{abstract}

Sensory experience leads to the initiation of a complex process of thinking about the world. The result of this process are the images of what surrounds us. We define this action as education. Because looking at the world from the perspective of sensual experience is the potential ability of every human being (Hannah Arendt), education becomes a tool enabling the simulation of the existing world and the one that may appear in the future. About who we are and where we are, who we will decide, the quality of the senses. The quality of the senses translates into the value of the cognitive process. The consequence of the quality of the cognitive process is the collection of information and knowledge. This sensual logic inscribes the action that classifies us people according to predisposition or available information that results from the quality of sensual functioning. As Leonardo da Vinci saw it: "Experience, the intermediary between creative nature and the human race, teaches what nature uses among mortals, that before the necessity of necessity one cannot act differently than reason, his teaching works."

Key words: sociology of education, senses, humanity, nature of senses, pedagogy, selection, culture, society, effectiveness

\section{Zmysły i edukacja}

Diane Ackerman w Historii naturalnej zmystów napisała:

Zjawiska wykraczające poza ludzki rozum rejestrowane są jednak również przez zmysły jako płomień w żyłach, drżenie serca czy odkładanie się złogów w kościach. Pozacielesne przeżycia dążą do wyeliminowania zmysłów, ale im się to nie udaje. 
Można patrzeć z nowej perspektywy, ale jest to wciąż wrażenie wzrokowe (...) Jednym z najgłębszych paradoksów gatunku ludzkiego jest to, że ta duża rozpiętość doznań, w których tak gustujemy, nie jest odbierana bezpośrednio przez mózg. Mózg jest milczący i ciemny, nic nie czuje, nic nie słyszy. Jedynym, co odbiera, są impulsy elektryczne. (...) Ciało jest transformatorem, który zamienia jeden rodzaj energii na inny - na tym polega jego geniusz. (...) Kilka zmysłów, które czują w sposób tak osobisty i improwizowany, a czasem wydają się dzielić nas od innych ludzi, sięgają daleko poza nas. Stanowią przedłużenie łańcucha genetycznego łączącego nas ze wszystkimi, którzy kiedykolwiek żyli ${ }^{1}$.

Zatem, kategoria pojęciowa „ucieleśnienie” wskazuje na istotę procesu edukacyjnego, a tym samym procesu recepcji rzeczywistości, o której nie możemy inaczej powiedzieć jak to, iż jest on, tenże proces, $\mathrm{z}$ jednej strony świadomego odczuwania, natomiast $\mathrm{z}$ drugiej - próbą refleksji nad zasobem zdobytych i zmagazynowanych bodźców na wielu poziomach recepcji, związanej bezpośrednio z kompetencjami poznawczymi.

Edukacja zatem, ujmując rzecz z tej perspektywy, stanowi celowe modelowanie natury ludzkiej (tego co przyrodzone) przez doświadczenie (jednostkowe bądź społeczne). A „przyrodzone” są elementy wyróżniające gatunek ludzki spośród świata zwierzęcego z takimi detalami, jak: świadomość, wolna wola, moralność, kreatywność, stopień kooperacji i zaufania, język, myślenie symboliczne, system wierzeń (czyli sposoby myślenia, odczuwania i działania, jako naturalne tendencje wrodzone, ale specyficzne gatunkowi ludzkiemu).

\section{Edukacja a modelowanie natury ludzkiej}

Całe życie ludzkie wydaje się polem walki, jaką toczą ze sobą ludzki intelekt oraz zmysłowy człowiek. J. Kozielecki opisał kiedyś spostrzeżenie młodego człowieka, który tę smutną i prozaiczną zależność odkrył:

młody człowiek, opętany misją tworzenia nowego ładu cywilizacyjnego [dostrzegł S.F.]... przy kuflu piwa: „Nawet najpiękniejsze idee rozbijają się o naturę ludzką, jak perły o betonową ścianę"2.

Mówiąc o modelowaniu natury ludzkiej, należy zwrócić szczególną uwagę na podstawową sferę działania, która bezpośrednio wpływa na zachowanie człowieka, to znaczy sferę zmysłową. Bo przecież z tego właśnie ośrodka płyną komunikaty zmuszające do poznawania świata albo zaniechania tych

${ }^{1}$ D. Ackerman, Historia naturalna zmystów, Warszawa 1994, s. 304-310.

2 J. Kozielecki, O człowieku wielowymiarowym. Eseje psychologiczne, Warszawa 1988, s. 29. 
działań. W istocie swojej, zmysły człowieka stają się transgresyjną perspektywą wykraczającą poza same receptory.

Kwestia natury ludzkiej, uwikłanej w proces edukacyjny, zmysłowego poznawania świata, kwestia funkcjonowania samych zmysłów to problem, który bezpośrednio związany jest z takimi zagadnieniami, jak: niezależność oraz uległości człowieka, problem wewnętrznej i zewnętrznej sterowalności, problem autonomii oraz konformizmu ${ }^{3}$. Bo przecież nawet poziom egoizmu człowieka wynika z jakości funkcjonowania zmysłów, co może jednostce pozwolić przetrwać albo nawet, jak to pisał Józef Kozielecki:

wnieść, swój niepowtarzalny wkład do wspólnoty. Egoistyczna motywacja umożliwia wykorzystanie potencjału intelektualnego i twórczego, wpływa na podejmowanie działań transgresyjnych, które rozwijają sztukę, naukę, które służą całej ludzkości

\section{Zmysły i filozofowie}

Zagadnienie zmysłów, ich roli, miejsca w funkcjonowaniu człowieka, znaczenia dla tworzenia rozmaitych rozwiązań teoretycznych, tak w naukach ścisłych jak i humanistycznych, to nic nowego. Już w V wieku przed naszą erą grecki filozof Empedokles z Akragas stwierdził, co zostało powszechnie przyjęte $\mathrm{w}$ greckiej filozofii, a my jesteśmy tego spadkobiercami, że nasze spostrzeganie, to znaczy odbieranie bodźców słuchowych, wzrokowych oraz czuciowych jest możliwe tylko w sytuacji bezpośredniego zetknięcia narządu zmysłu z obiektem. Można powiedzieć, że poznawanie świata odbywa się w ramach procesu, w którym to zmysły dokonują ",selekcji” dopływających do nich treści w fazie spostrzegania, interpretowania, czy zapamiętywania.

Pogląd ten w rozwoju myśli naukowej miał wielu prekursorów, zwłaszcza w dziejach filozofii greckiej, w której kształtowały się rozmaite metody rozumienia świata oraz rozumienia praw, jakimi się rządzi. I tak, między innymi, usiłowano zdefiniować takie kategorie pojęciowe, jak „prawda” czy "człowiek". Decydujący wpływ miał tutaj Arystoteles ze swoją koncepcją filozofii pierwszej oraz rozumieniem doświadczenia i jego ograniczeń. Nie można nie doceniać w tym względzie również innych filozofów greckich, jak Platon czy Parmemides, wraz z jego pomysłami, które zaliczane są do początków krytycznego myślenia o doświadczeniu i możliwości poznawania prawdy definiowanej jako adaequatio intellectus et rei.

\footnotetext{
3 Tamże, s. 27.

${ }^{4}$ Tamże, s. 26-27.
} 
Demokryt z Abdery w jednym ze swoich dialogów filozoficznych, który toczy się między umysłem traktowanym jako organ nadzmysłowy a zmysłami, dostrzegł, że produkty, spostrzeżenia tych ostatnich (zmysłów) są iluzoryczne, bo uzależnione od stanów naszego ciała, a ich działanie częściowo wynika z umowy społecznej. Jednak w dialogu tym do zmysłów wydaje się należeć ostatnie słowo, gdyż z jednej strony umysł wskazuje na iluzoryczność zmysłowych doświadczeń, z drugiej jednak - to ze zmysłów umysł czerpie "swoją oczywistość". Być może to zdrowy rozsądek podpowiadał filozofowi, że te dwa jakby odrębne światy nie mogą bez siebie poprawnie funkcjonować, gdyż: "kiedy świat nadzmysłowy zostaje odrzucony, jego przeciwieństwo, świat zmysłowy również przestaje istnieć. Co istotnie jest prawdą" ${ }^{5}$.

Przedstawione stanowiska stanowią rodzaj myślenia, które daje podstawy w przeciwieństwie do współczesnych poglądów, zwłaszcza w naukach humanistycznych jak i społecznych usiłujących nauczyć nas żyć bez podstaw ${ }^{6}$.

\section{Kompetencje poznawcze a zmysłowe i niepewność}

Kategoria pojęciowa „ucieleśnienie” jest pojęciem wskazującym na istotę procesu edukacyjnego, a tym samym procesu recepcji rzeczywistości, o której możemy inaczej powiedzieć, że jest to: proces świadomego odczuwania oraz refleksji nad zasobem zdobytych i zmagazynowanych doświadczeń. Proces ten przebiega na wielu poziomach recepcji zmysłowej, zwiąanej bezpośrednio z kompetencjami poznawczymi. To z jakości istnienia tychże kompetencji wynika gwarancja zaistnienia ,jutra”. Bo przecież jak napisał Pierre Teilhard de Chardin, jeden z najwybitniejszych w dziejach ludzkości, teolog, filozof, antropolog i paleontolog: „czy jednak nie mając gwarancji jutra, moglibyśmy żyć dalej, skoro właśnie nam - być może po raz pierwszy w historii wszechświata - dana została zdolność przewidywania przyszłości?"7

Chodzi o przyszłość „zmagazynowaną" w postaci potencjału drzemiącego w "czuciu" i rozumieniu tego co nas otacza. Jednak, o czym wspomina filozof, to przewidywania mogą jednak okazać się fałszywe co do swej trafności, a to ze względu na niepewność rodzącą się w kontekście zmysłowego życia. Niepewność ta jest następstwem oddalenia się od bezpośredniego doświadczenia bądź natłoku piętrzących się rozmaitych wrażeń zmysłowych,

${ }^{5}$ H. Arendt, Myślenie i namyst moralny, [w:] H. Arendt, Odpowiedzialność i władza sązenia, Poznań 2006, s. XIV.

${ }^{6}$ C. Woźniak, Okamgnienie. Doświadczenie źródłowe a granice filozofii, Kraków 2008, s. 17.

${ }^{7}$ P. Teihard de Chardin, Problem działania, [w:] P. Teihard de Chardin, Pisma wybrane, Warszawa 1967, s. 115. 
których nie można uporządkować. Jak podkreślił Teihard: „A zatem przede wszystkim dokucza nam ogrom i mnogość" ${ }^{\prime 8}$.

Warto w tym miejscu wskazać trendy panujące w światowej literaturze socjologicznej dotyczące roli i miejsca cielesności ludzkiej oraz jej sile determinującej. I tak, między innymi, Chris Shilling, profesor socjologii na Uniwersytecie Portsmouth w wydanych przez siebie książkach, między innymi: Changing Bodies: Habit, Crisis and Creativity (Published in association with Theory, Culture, Society), The Body in Culture, Technology, Society, czy też The Body and Social Theory, podejmuje problem "ciała”, a raczej przygląda się jego istocie jako odbiornika informacji zewnętrznych, niezbędnych człowiekowi $\mathrm{w}$ celu ulokowania się $\mathrm{w}$ przestrzeni życiowej.

Uczony ten traktuje ciało wyposażone w receptory jako element o decydującym wpływie na kształt społeczeństwa, kultury, powstających i rozwijających się technologii, a zatem ludzkiej wiedzy. Wskazuje on na "ciało" jako podstawowy czynnik socjalizacji, a co za tym idzie - zdolności twórczego zaangażowania się ludzi w otaczający świat istnienia ludzkiego, świadomego ",ja" ${ }^{\prime 9}$.

\section{Zmysły \\ i zdolność do przekształcania świata $\mathrm{w}$ ideologie}

Chyba najbardziej brzemienne w skutki odkrycie ludzkości wiązało się ze znaczeniem, że odbierane przez człowieka treści można przekształcać zgodnie z własnym upodobaniem, a w taki sposób przekształcony świat można „zinstytucjonalizować”. „Instytucjonalizację", o której myślę, można traktować jako produkt uzurpacji określonych grup społecznych lub jednostek. Działania te mają na celu "kolonizację zmysłów”. Wynika ona z własnego interesu określonych grup społecznych w orzekaniu o rozmaitych przestrzeniach życia, na przykład estetycznej, gdzie orzekanie będzie prowadziło do kształtowania tego co „ładne” albo „brzydkie” w kreowaniu otoczenia; orzekanie w przestrzeni etycznej będzie z kolei sprowadzało się do wskazywania tego co "dobre” albo co „złe” w przekonaniu orzekających.

Łączenie takich płaszczyzn, jak przestrzenie widzenia, czucia, czy słyszenia zostały nierozerwalne $\mathrm{w}$ historii ludzkości, wtłoczone $\mathrm{w}$ przestrzeń ideologizacji życia, między innymi w sytuacji sprawowania władzy, czy też uczestniczenia $\mathrm{w}$ wyznawaniu religii. A w przestrzeni związanej z naszym kręgiem kulturowym najczęściej eksploatowanym motywem, krytycznie

${ }^{8}$ Tamże, s. 114.

9 Zob. C. Shilling, Changing Bodies: Habit, Crisis and Creativity (Published in association with Theory, Culture, Society), London 2008; tegoż, The Body in Culture, Technology, Society, London 2005; tegoż, The Body and Social Theory, London 2005. 
nastawionym do roli zmysłów, stała się alegoria jaskini platońskiej, gdzie zmysły i "ciało" stały się synonimem niedoskonałości czy wręcz ułomności. Ułomność ta, to niewidoczny łańcuch trzymający nas w materialnym świecie pozoru, który nie jest światem rzeczywistym. To, co składa się na zmysłowy świat zmienia się i w efekcie ginie. Ta chwilowość, przelotność, to cechy niedoskonałości materialnego świata, który nas otacza. Natomiast, cechami świata doskonałego, świata trwałego stały się: niezmienność oraz wieczność nie dająca się ograniczyć czasem i przestrzenią, i nie dająca się wyobrazić.

\section{Współczesna edukacja, zmysły i selekcja}

Dlaczego tak bardzo szczególne miejsce w edukacji zajmują zmysły? Odpowiedź wydaje się banalnie prosta. Doświadczenie zmysłowe bardziej udostępnia się nam, bardziej „bierzemy je w posiadanie”, niż kreujemy je sami. Ludzki organizm za pomocą zmysłów „połykających" świat w procesie doświadczania jest permanentnie nastawiony na odbieranie informacji w postaci bodźców: świetlnych, akustycznych, chemicznych lub mechanicznych. Doświadczenie to będące wynikiem działania zmysłów, poprzez celowe działania edukacyjne może stać się świadomym procesem, w którym człowiek głęboko, wewnętrznie i całkowicie będzie usiłował zrozumieć odczucie wartości i sensu.

Wartość edukacyjną doświadczenia zmysłowego możemy wyraźnie dostrzec w chwili, kiedy przyporządkujemy mu refleksję mogącą posłużyć do wytworzenia warunków w celu spontanicznego wypowiadania się i rozwijania możliwości komunikacji.

To edukacja w ramach uzmysłowionego świata może doprowadzić do stworzenia:

1) indywidualnej i osobistej gotowości do postrzegania zmysłowej rzeczywistości, właściwej poszczególnym jednostkom;

2) zindywidualizowanej siły wyrazu, ekspresji przeżywania doświadczenia;

3) poczucia bezpieczeństwa oraz stabilności, koniecznych w sytuacji doświadczeń granicznych, rozumianych jako wystawienie się na ryzyko poznania czegoś ",nowego";

4) takiego edukacyjnego programu, który organizuje doświadczenie uwzględniające często występujące zjawisko frustracji, jako niemożności uzyskania wiedzy, czegoś nowego;

5) ukierunkowania procesu edukacyjnego na podkreślenie osobistego wymiaru doświadczenia;

6) pomostu edukacji i świata codziennych doświadczeń zmysłowych. 
Uzmysłowiona edukacja to w końcu wewnętrzny wysiłek, który chce podjąć ryzyko i wypróbować własne siły z niezwykłym lub nieznanym. Doświadczanie naznaczone jest przez napięcie uczuć życiowych, uwalnia od powszedniości dnia codziennego i stawia nas przed tym co nadchodzi, między pewnością (bezpieczeństwem) własnego działania i niepewnością tego co się staje - cennego nie dla mocy panowania nad nim, lecz "rozkoszy lęku".

\section{Kolumb, zmysły oraz edukacyjny hazard}

Jednym z najciekawszych modeli obrazujących zaangażowanie zmysłowe człowieka $\mathrm{w}$ proces przekształcania świata można dostrzec $\mathrm{w}$ propozycji sformułowanej przez Józefa Kozieleckiego, a określonego przez niego jako „Model Kolumba”. Ten jeden z najwybitniejszych polskich humanistów dokonał analizy wartości edukacji, czyniącej z doświadczenia zmysłowego podstawę do sformułowania metod oraz narzędzi oddziaływania w aspekcie ich skuteczności.

Losy Kolumba, jego historię, a raczej historię jego odkryć można potraktować jako model edukacji opartej na logice oraz funkcjonowaniu zmysłów. Model taki można dostrzec w rozwiązaniach edukacji domowej, jako działania szczególnie nastawionego na eksplozje wrażliwości człowieka. O wspominanym tutaj rozwiązaniu pisał prekursor tego rozwiązania w Polsce M. Budajczak ${ }^{10}$.

Chodzi o takie rozwiązanie edukacyjne, które wprost wpisuje się w funkcjonalność i dysfunkcjonalność zmysłową człowieka oraz logikę rozwojową, według której podejmowane działania powinny podążać. Jak pisał Kozielecki:

Kolumb podjął jedno z najambitniejszych działań człowieka: postanowił odkryć nowy szlak morski do Indii, płynąc na zachód; wykonanie go pozwalało rozszerzyć dotychczasowe możliwości podróżowania. Jego zamiar był w wysokim stopniu ryzykowny i niebezpieczny. Ani ówczesne statki, ani aparatura pomiarowa, ani przygotowanie załogi nie pozwalały na osiągnięcie celu z całą pewnością. W rezultacie Kolumb nie zrealizował swoich planów. Osiągnął wynik nie zamierzony, pragnął dotrzeć do Indii, tymczasem odkrył Amerykę. Transgresja, której się podjął, okazała się korzystna dla ludzkości. W wielu wypadkach jednak podobne działania doprowadzają do skutków dramatycznych. Wycinanie lasów przez Majów czy Khmerów dało im tani opał, ale jednocześnie - zupełnie nieoczekiwanie - spowodowało głęboką erozję gleby i w konsekwencji nagły upadek ich cywilizacji. Niespodzianka znajduje się tylko o krok od fiaska ${ }^{11}$.

${ }_{10}$ Zob. M. Budajczak, Edukacja domowa: społeczne konteksty kształcenia się w rodzinnym gronie, poza instytucjonalnym środowiskiem szkoty, Poznań 2002.

${ }^{11} \mathrm{~J}$. Kozielecki, O człowieku wielowymiarowym, s. 117. 
Jak pisał dalej Józef Kozielecki:

Analogia między życiem Kolumba a czynami człowieka jest jednak znacznie głębsza. Zgodnie ze źródłami historycznymi żeglarz ten do końca życia wierzył, że osiągnął planowany cel, że dotarł do Indii płynąc na zachód. Tłumił wszelkie myśli o odkryciu nowego kontynentu. Podobnie sprawca, który doznał frustracji, stara się często przekonać siebie i innych, że odniósł sukces, że czyn zamienił w wyczyn ${ }^{12}$.

I tak to właśnie, używając w dalszej części słów J. Kozieleckiego,

Model Kolumba, sprawcy niedoskonałego, pozwala wyjść poza optymizm prometejski i pesymizm syzyfowy, poza niezawodność konkwistadora i daremność trudu egzystencjalisty ${ }^{13}$.

\section{Wnioski}

Posiłkując się metaforą J. Kozieleckiego i traktując edukację w kategoriach „Modelu Kolumba”, dochodzimy do przekonania, że celem tejże edukacji zakorzenionej w logice zmysłów jest przekraczanie granic doświadczenia płynącego właśnie ze zmysłów. Istota przyjęcia takiego modelu edukacyjnego wymaga wskazania następujących możliwych scenariuszy.

1. Wielki sukces - przy określonych korzystnych warunkach sprzyjających prawidłowemu poznawaniu można osiągnąć wynik o najwyższej wartości, co może rozszerzyć ludzką wiedzę lub zwiększyć zakres władzy. Siłą napędową staje się nadzieja na zdobycie wiedzy najwyższej jakości.

2. Mała szansa sukcesu - okoliczności sprzyjające poznawaniu świata na poziomie najwyższej jakości stanowią rzadki przypadek. Prawdopodobieństwo osiągnięcia celu jest zatem niewielkie.

3. Wielka klęska - nieszczęśliwe zbiegi okoliczności prowadzą do niepowodzenia. Klęska stwarza zagrożenie tak dla poznającego, jak i jego otoczenia.

4. Duże prawdopodobieństwo niepowodzenia - niepożądane stany jakość zmysłów, jak i jakość warunków pozostawiają wiele do życzenia, co sprawia zwiększenie potencjalnego zagrożenia

Przedstawione tutaj cztery scenariusze edukacyjne biorą swe źródło w rozważaniach odkrywców, którzy chcą osiągnąć sukces. Aby jednak do tego doszło, muszą założyć także sytuację możliwej porażki bądź odkrywania niezamierzonych miejsc ani związków przyczynowych. Dzięki takiemu działaniu zostają przewidziane wszystkie możliwe do zaistnienia scenariusze wydarzeń. Dlatego, system edukacyjny, który zamierza osiągnąć daleko idą-

\footnotetext{
${ }^{12}$ Tamże, s. 118.

${ }^{13}$ Tamże.
} 
cy sukces, należy oprzeć na szczegółowej selekcji, w ramach której każdemu podmiotowi edukacyjnemu przypisuje się proporcjonalnie do jego naturalnych predyspozycji możliwy plan przyszłych dróg rozwoju. Tenże plan powinien wpisać $\mathrm{w}$ mechanizm swego działania spore prawdopodobieństwo poniesienia znacznych strat, co leży w logice postrzegania zmysłowego, lecz nikt nie miał nigdy wątpliwości, że każde działanie edukacyjne ma w sobie coś z hazardu „ryzykownego przedsięwzięcia”, ryzykownej inwestycji w zmysłowego człowieka. Jednakże, podejmowanie działań, wraz z jednym z najistotniejszych czynników wynikających z zaangażowania jakim jest poczucie sprawstwa, o którym w kontekście edukacji menadżerskiej pisał S. Banaszak, przy uwzględnieniu wspominanego ryzyka, to niewątpliwie źródło sukcesu życiowego opartego na uzmysłowionej, realnej edukacji, konstruującej możliwą do zaistnienia przyszłość ${ }^{14}$.

\section{BIBLIOGRAFIA}

Ackerman D., Historia naturalna zmystów, Warszawa 1994.

Arendt H., Myślenie i namyst moralny, [w:] H. Arendt, Odpowiedzialność i władza sądzenia, Poznań 2006.

Arendt H., Odpowiedzialność i władza sązenia, Poznań 2006.

Banaszak S., Edukacja menedżerska w spoteczeństwie wspótczesnym. Studium teoretyczno-empiryczne, Poznań 2011.

Bettelheim B., Rany symboliczne. Rytuaty Inicjacji i zazdrość męska, Warszawa 1989.

Budajczak M., Edukacja domowa: spoteczne konteksty kształcenia się w rodzinnym gronie, poza instytucjonalnym środowiskiem szkoły, Poznań 2002.

Da Vinci L., Pisma wybrane, Warszawa 1958.

Danek D., Ludzkie. Międzyludzkie (wstęp do przekładu książki) [w:] B. Bettelheim, Rany symboliczne. Rytuaty Inicjacji i zazdrość męska, Warszawa 1989.

Kozielecki J., O człowieku wielowymiarowym. Eseje psychologiczne, Warszawa 1988.

Shilling C., The Body and Social Theory, London 2005.

Shilling C., The Body in Culture, Technology, Society, London 2005.

Shilling C., Changing Bodies: Habit, Crisis and Creativity (Published in association with Theory, Culture, Society), London 2008.

Teihard de Chardin P., Problem dziatania, [w:] P. Teihard de Chardin, Pisma wybrane, Warszawa 1967.

Woźniak C., Okamgnienie. Doświadczenie źródłowe a granice filozofii, Kraków 2008.

${ }_{14}$ Zob. S. Banaszak, Edukacja menedżerska w społeczeństwie wspótczesnym. Studium teoretyczno-empiryczne, Poznań 2011, s. 276. 